\title{
TRADITION PATTERNS OF ANTENATAL CARE AND MATERNAL HEALTH IN MAMFE: UNDERSTANDING THE SOCIO-CULTURAL FACTOR OF MATERNAL MORTALITY IN RURAL CAMEROON
}

\author{
Ndoh Lawrence Nkwain $\mathbf{P h D}^{1}$, Aziamin Asongu Norah $\mathbf{P h D}^{2}$
}

\author{
Celestine Arreytta RN, BSN, FNP ${ }^{3}$ \\ ${ }^{1}$ Instructor, Department of Sociology and Anthropology, Faculty of Social and Management Sciences, \\ University of Buea; Research Fellow, Centre for Population Studies and Health Promotion. \\ ${ }^{2}$ Research Officer, Ministry of Scientific Research and Innovation; Lecturer, University of Yaounde 1, \\ ${ }^{3}$ Celestine Arreytta, Registered Nurse, Bachelor of Science in Nursing, Family Nurse Practitioner,
}

Nurse Manager at Wellbridge of Clarkston, Michigan USA,

Article DOI: https://doi.org/10.36713/epra9148

DOI No: 10.36713/epra9148

\begin{abstract}
From the case study of Mamfe, this research has been tailored to highlight and examine the influence of traditional patterns of antenatal care on maternal morbidity and mortality in rural Cameroon. The country is one of the underachievers of the MDGs with strong socio-cultural attachment and a consequential high reliance on traditional patterns for antenatal care. Understanding the influence of this reliance gives a more complete view of the socio-cultural factor critical towards underlining the underlying determinants of maternal deaths. The rationales behind most traditional antenatal beliefs and practices, some of which have been highlighted in this work, scarcely correspond to the biomedical norms for useful maternal healthcare. They reportedly fulfill more superior and collective purposes that understandably prevail over maternal health. Non-respect for these traditional imperatives puts transgressors at odds with the community. Given their understandable vulnerability during pregnancy, expectant women are therefore predisposed to a higher risk of complications and death. The research was both cross-sectional and exploratory, constructed on a qualitative design. Non-probability purposive sampling was used to constitute a sample size of 140 participants. Research techniques employed included in-depth interviews, FGDs and direct observation. We discovered that expectant women widely attended conventional antenatal consultations but were rigorously constraint to respect and adhere to beliefs and practices for traditional maternal care. As such widespread facilitybased deliveries in rural settings heralded as the ideal solution by many does not necessarily limit the influence of the sociocultural factor on MMR.
\end{abstract}

KEY WORDS: rural Cameroon, traditional patterns, influence, antenatal care, maternal mortality

\section{INTRODUCTION}

Maternal death reduction is a fundamental indicator for development in several countries around the world (1). Significant attention on the healthcare of women has therefore been placed on strategies to curb deaths relating to pregnancy and childbirth. This was considerably underscored by the Millennium
Development Goal 5 (MDG5), which described the necessity to extensively reduce global maternal mortality rates. With current estimates of mortality ratios standing at more than 1000 per 100000 live births (2), Sub-Saharan Africa has understandably been the choiced terrain for many researches and intervention programs seeking optimal maternal 
healthcare. These have undoubtedly been the trigger for the gradual but observable maternal mortality decline in the continent within the last decade $(3,4)$. Nevertheless, a great deal is yet to be done given the current alarming situation (2). To ensure that complications are detected and managed on time, focus has long been placed on identifying and dealing with obstetric causes of maternal morbidities and mortalities and barriers to exploiting clinical healthcare during pregnancy. However, maternal mortality is affected directly or indirectly by several factors either at individual or community levels reflecting variations in both ratios and causes between and within countries. In Cameroon, the MMR stood at 430, 669 and 782 per 100,000 live births in 1998, 2004 and 2011 respectively. With about $60 \%$ of its population under 25 years and a fertility rate of 5.1 children per woman, the country is currently ranked $18^{\text {th }}$ amongst countries having the highest maternal death statistics (5). The situation is explicably worse in rural communities commonly characterized by high reliance on traditional antenatal care. This reliance understandably weighed on the country's underachievement of the said MDG 5. The rationales behind most traditional antenatal beliefs and practices, some of which have been highlighted and examined in this paper, scarcely correspond to and at times even go against biomedical norms for maternal healthcare. Given their logical vulnerability during pregnancy, expectant women are therefore predisposed to a higher risk of complications and death. Addressing this issue particularly could be cardinal to the attainment of the more challenging Sustainable Development Goal 3 (SDG 3) that targets a further reduction of MMR to less than 140 per 100,000 live births by 2030 in high burden countries like Cameroon $(6,7)$. There is an increasing interest on the correlation between maternal mortality and its socio-cultural determinants within rural settings of developing countries. However, this is largely focused on determinants constituting barriers to the exploitation of skilled obstetric assistance in specialized facilities. This paper therefore attempted to highlight traditional patterns of maternal healthcare and explore their influence on pregnancy outcomes in rural areas. To this effect, we sought to identify local beliefs and practices employed during traditional antenatal care, determined extent of community adherence and their influence on the vulnerability of women to obstetric complications. Reducing high MMR is therefore reliant on basically dealing with the socio-cultural contexts of women during pregnancy. This may be fundamental to understanding the complete extend of the socio-cultural factor of maternal mortality and development of more effective control schemes.

\section{BACKGROUND}

Mamfe is the chief town of the sub-division bearing the same name, situated in Manyu Division in the northern part of the South West Region of Cameroon. The town is located some 60 kilometers from the country's territorial borderline with the neighboring Federal Republic of Nigeria. Notwithstanding its increasingly cosmopolitan nature, a significant proportion of the population consists of the native Bayang ethnic group. The custodians of the land are the elderly and have the responsibility of maintaining and transmitting socio-cultural heritage. Questioning or opposing any aspect of the latter constitutes a taboo. Hence, the existence of certain traditional beliefs and practices during maternal healthcare whose raison d'être is not fully understood. Medical plurality is a reality in Mamfe given the many public and private health facilities doted particularly at the centre of the town. Most often patients in these facilities have either tried it out at home or with traditional healers and have not been satisfied or relieved from their sufferings. Even at that, conventional alternatives are sought alongside ethnomedicine reflecting strong attachment to traditional values. Here, the notion of totemism is somewhat particular given that individuals can have personal totems for protection. The belief in witchcraft is so strong that almost all sad events or unwanted experiences are attributed personalistic origins. It is believed that through the assistance of a physical entity, evil spirits can have access to and harm anyone in the community. However, it is equally believed that traditionally certain actors in the local health system are knowledgeable enough to appropriately use particular rites to prevent such happenings or minimize their consequences. These cultural elements interfere in the constitution of the traditional package for maternal healthcare and pregnancy outcome as shall be examined subsequently.

\section{MATERIALS AND METHODOLOGY}

This cross-sectional and exploratory research was reliant on a qualitative design given the minimal available literature for reference on both subject and place of research coupled with the necessity to explore personal experiences and opinions of many subjects. Medical plurality has long been a reality in Mamfe with clinical, traditional and faith-based facilities directly intervening on maternal healthcare and childbirth. Hence, the justification for our choice of Mamfe given the non-existence of the closely related and frequently researched question of unavailable skilled obstetric 
services. Conversely, unanswered preoccupations still persist on the relationship between pregnancy outcomes and reliance on traditional antenatal care. This was made evident from our documentary research of available literature that dealt with the socio-cultural context as a factor of MMR. Fieldwork was done to give room for collection of primary data on the underexploited influence of traditional care in pregnancy. Pretesting for reliability and validity of research tools was done in the rural town of Kumba having similar characteristics with our research site. Non-probability purposive sampling was employed to constitute a sample size of 140 participants comprising of custodians of the land, tradipractitioners especially Traditional Birth Attendants (TBAs), community health workers, native mothers expecting a child or having at least one delivery experience, friends and relatives of maternal mortality victims. In-depth interviews were conducted with 85 respondents. During these interviews we probed for maximum collection of required data. Triangulation for authentication and dependability of data was done through the use of two other qualitative techniques including Direct Observation and Focus Group Discussion (FGD). Five FGDs were conducted with between 8-12 participants in each case. At their place and time of convenience, respondents were free to express themselves in English, Kenyang, or the widely spoken Pidgin English.

\section{ETHICAL CONSIDERATIONS}

Prior to fieldwork, a research authorization was obtained from the Department of Anthropology at the University of Yaoundé 1, under whose tutelage the research was carried out. This was followed by clearance from civil and traditional authorities on the ground. Every prospective participant, on the basis of the earlier mentioned criteria of selection, was preliminarily informed on the research purpose, procedure, benefits and inconveniences. The right to participation and non-participation was expressed. An informed consent was requested and all who were sampled consented. Assurance of confidentiality was built on anonymity of identity.

\section{DATA PROCESSING AND ANALYSIS}

Audio recordings from interviews and FGDs were faithfully translated and transcribed word for word in English. They were then stored using Microsoft word files along with related field notes. This was followed by codification. Closely related parts of the data were grouped and given particular coloration leading to the the development of patterns and emergence of themes. An interpretative approach was established centered on the narrative analysis which looks at beliefs, customs, values and social contexts of when, how and why sequence of events unfolded. All these enabled us to uncover trends directed towards achieving the objectives of our research.

\section{RESULTS AND DISCUSSION}

Medical plurality has given rise to medical complementarity and syncretism in rural settings. Community members select and adhere to particular beliefs and practices within the local health system depending on their individual and above all collective interests. Total reliance on a single sub-health system for maternal healthcare is disadvantageous and scarcely done. Data from in-depth interviews reveal that there is widespread clinical antenatal consultation and facilitybased delivery. These facilities are said to be more adapted to appropriately handle unforeseen circumstances and easily ensure save delivery. An underlying influence to this is an increasing level of education for women in rural areas and a corresponding improvement in levels of awareness towards the benefits offered by these facilities. The constant risk for the occurrence of unforeseen circumstances requiring biomedical interventions during pregnancy is also a factor. The commitment of health personnel when solicited for such emergencies on women who ignored clinical antenatal care is reportedly not always the best. To be on the safe side, most women go for antenatal consultations. Their high demand is in contradiction to a widely emphasized claim that minimal utilization of clinical facilities in rural areas caused by socio-cultural factors is at the origin of the high MMR. However, these women at the same time largely observe strict respect towards traditional beliefs and practices for maternal care and delivery. Enforced by Traditional Birth Attendants and other actors in the traditional healthcare system, non-respect for these traditional imperatives puts women at odds with the community, a situation of social alienation desired by none. The family is stigmatized and its members are denied access to certain benefits associated to childbirth in the public sphere. Furthermore, it is believed that a child's spiritual connection with the land and its protective deities is fortified during assistance provided by TBAs. For socio-cultural reasons therefore, recommendations for traditional care during pregnancy and delivery are prioritized. Exploitation of other services is only possible when they either complement or are not in contradiction. As such, the usefulness of traditional antenatal care goes beyond maternal wellbeing. Some of the beliefs and practices are reportedly destined to 
maintain and uphold the socio-cultural equilibrium of the entire group. This is a superior cause that understandably must prevail over that of a single expectant woman's health in a case where there is conflicting interests. Highlighting some of these beliefs and practices and examining their interconnection with maternal health gives a more complete view of the socio-cultural factor in terms of its influence on MMR. These include:

\section{ACCUSATION OF INFIDELITY DURING BREECH DELIVERY}

Infidelity especially during pregnancy is culturally forbidden in Mamfe. It is believed to be the most probable cause of breech delivery; a situation when the baby starts coming out with the legs or bottom during delivery. It is believed that the baby's breeched position can only change after the mother confesses her unfaithful act. This is because the child is thought to have lost his purity and is unhappy with the mother. As such, he is thought to be breeched deliberately to punish the mother and let others know the evil act she committed. The confession is believed to calm the baby and cause him to cooperate with the attendant's efforts to bring him out. Such accusations are generally denied. This is usually not helpful given that the more a mother insists on her innocence, the longer she remains undelivered of. Under normal circumstances, breech delivery is a difficult exercise for both mother and attendant. This interrogation makes it the more difficult and risky. The risk is said to be high given the illustration that without the use of antibiotics a woman still in labour hours after the rupture of her membranes is at risk of serious infections (8). The proportion further rises to almost $100 \%$ of women who remain undelivered after twenty four hours. Described by an informant as traumatic, this situation is said to cause loss of energy and fatigue. The posture a child assumes in the womb, just before and during delivery, is of great importance to the physical efforts that the mother is required to make and the outcome of the delivery (9). Breech delivery could be life-threatening if measures are not taken to carry out a caesarean section. Acceptance of incompetence and effecting appropriate referrals to health facilities with more suitable services is usually delayed. By prioritizing the necessity to maintain social cohesion over the health of mothers, it is obvious that this practice has an undesired influence on maternal health every time it occurs as highlighted by the following testimony from a deceased relative:

[...tradition is not always fare to us women, especially when it comes to pregnancy and childbirth. We tolerate a lot of things that are not really helpful to us directly as mothers. I might not understand what causes a child to be breech, but $i$ know that it has nothing to do with unfaithfulness. That is how we lost a family sister because her child was breeched and the traditional attendant wasted so much time trying to discover the truth about an unfaithful act that did not exist. When she was finally taken to a nearby clinic, it was already too late].

\section{HARNESSING SUPERNATURAL POWERS OF UNBORN CHILDREN}

Individual ownership of totems for supernatural protection is thought to start while in the womb. This may not necessarily be the same with the mother's, given the belief that inheritance of totems could be from any relative. Foetal and maternal totemic incompatibility is a believed cause for many illnesses experienced during pregnancy. As for twin children, they are believed to have supernatural powers even while in the womb. Many maternal complications too have been attributed to unborn children's totemic acts. Performing a rite for harnessing the totemic powers of pregnant women and their unborn child(ren) is said to be imperative for the mother's survival during this period. It reportedly transforms these powers into a booster for maternal immunity against diseases and evil attacks. However, this rite is recommended at an advanced stage of the pregnancy to give room for proper foetal totemic development given its protective importance. Until then, the mother's health is therefore at the mercy of the supernatural powers of her unborn child(ren). By implication, nothing should be done to treat or remedy certain health issues connected to this. The unbelief of health personnel in conventional facilities on this and other pregnancy-related sociocultural stance, further justifies maternal inaction and neglect. The outcome of neglected illnesses during pregnancy can only be detrimental to maternal health and a trigger to obstetric complications. Once again, through socio-cultural influence, other concerns are unconsciously prioritized at the detriment of maternal health as highlighted by the following testimony from 62 year old TBA:

[...You must have heard about the Bayangis and their totems, its our reality... The death of a pregnant woman can result from dispute between her totem and that of her unborn child. This is frequent when both totems are different and incompatible. When this happens, the mother is the one that is affected the most as she 
can suffer from resulting health consequences like bleeding and abdominal pain. There is usually no call for alarm when these occur, it simply tells us that it is time to carry out the harnessing rite. It becomes dangerous only when there is delay. I have experienced this many times]

\section{SCARIFICATION DURING PREGNANCY}

Scarification is highly integrated into many preventive and therapeutic procedures of African Traditional Medicine. In Mamfe, it is a frequently employed technique for spiritual protection during pregnancy. Socio-culturally, witchcraft here is thought to be a dominant factor for maternal deaths. Given that the unborn child's totem is not yet fully developed to guarantee optimal spiritual protection, his protection is temporally ensured by the mother's. This is thought to weaken her personal protective ability. As such, during pregnancy women generally seek fortification from supernatural sources offered by TBAs and other tradipractitioners. The widely employed scarification is reportedly the most appropriate for these women. Such knowledge on therapeutic preference is certainly build and transmitted from past experiences. The equipments used are usually the same for everybody. They are said to be secret and have been handed down from previous generations. Much manipulation, as is the case during sterilization, can make these equipments to lose their therapeutic ability. Thus they are used over and over from one patient to another with little or no efforts to sterilize. The sought after spiritual protection may be acquired as desired. However, it goes without saying that this greatly increases the risk of viral and bacterial contamination. Infection is a great concern during pregnancy if left undetected and untreated $(\mathbf{1 0 , 1 1})$. It can lead to many obstetric complications and death. Once again, local beliefs and practices employed during traditional antenatal care have proven to influence maternal health even while conventional facilities are exploited.

\section{CONCLUSION}

Studies on the causes of MMR around the world have revealed several direct and indirect factors (12, 13), none of which if addressed alone can lead to substantial and sustainable reduction of pregnancy and childbirth related deaths. However, the preponderance of certain factors in particular regions necessitates disproportionate interest and resource deployment. In rural Cameroon, the socio-cultural factor has been identified as the predominant underlying cause of the prevailing MMRs. Previous researches have pointed at strong adherence to local cultural beliefs and practices as a cause to low facility-based delivery $(14,15,16$, 17) and a consequential higher obstetric complications and deaths. Our research in Mamfe reveals the availability of many specialized conventional facilities whose exploitation is not culturally forbidden unless it opposes or transgresses the norms for traditional antenatal care. As such, we discovered that expectant women widely attended conventional antenatal consultations but were rigorously constraint to respect and adhere to traditional beliefs and practices for maternal healthcare. The rationales behind most of these traditional imperatives scarcely correspond to the biomedical norms for healthy maternal care. Usually committed to serve other socio-cultural purposes as illustrated above, we established that a good number of these traditions increase vulnerability to obstetric complications and death. We therefore found out that widespread facility-based delivery under such rural circumstances does not limit the influence of the sociocultural factor on maternal health. This presents a more complete understanding of the socio-cultural factor that may help stakeholders to design more appropriate interventions in the fight to reduce MMR.

\section{REFERENCES}

1. Riley I.D., Hazard R.H., Joshi R., Chowdhury H.R., Lopez A.D., (2019), Monitoring progress in reducing maternal mortality using verbal autopsy methods in vital registration systems: what can we conclude about specific causes of maternal death? BMC Med. 17:104.

2. World Health Organization (WHO) World Health Report (2005), Make Every Mother and Child Count. Geneva.

3. AbouZahr C., Wardlaw T., (2001), Maternal mortality at the end of a decade: signs of progress?. Bull World Health Organ., 79 (6): 573-596.

4. Hill K., Thomas K., AbouZahr C., Walker N., Lale S., Inoue M., Suzuki E., (2007), Estimates of maternal mortality worldwide between 1990 and 2005: an assessment of available data. Lancet., 370: 13111319.

5. MINSANTE. Planification familiale: (2015), Plan operationnel du Cameroon 2015-2020

6. WHO. (2016), Maternal mortality.

7. United Nations. Goal 3: (2015), sustainable development knowledge platform.

8. Maine, D., Murat Z. A., Victoria M.W., \& Angela K., (1997), the design and evaluation of maternal mortality programs. Columbia University

9. WERNER, D., (1987), where there is no doctor. A village health care handbook for Africa. London, Macmilan.

10. Robinson D.P., Klein S.L., (2012), Pregnancy and pregnancy-associated hormones alter immune 
responses and disease pathogenesis. Horm Behav. 62:263-271

11. Pazos M., Sperling R.S., Moran T.M., Kraus T.A., (2012), The influence of pregnancy on systemic immunity. Immunol Res. 54:254-261

12. McCarthy J., Maine D.A., (1992), framework for analyzing the determinants of maternal mortality. Stud Fam Plan. 23:23.

13. Alvarez J.L, Gil R., Hernández V., Gil A., (2009), Factors associated with maternal mortality in subSaharan Africa: an ecological study. BMC Public Health. 9:462.

14. Ahmed O.A., Odunukwe N.N., Akinwale O.P., et al. (2005), Knowledge and practices of traditional birth attendants in prenatal services in Lagos State, Nigeria. Afr J Med Sci. 34(1):55-58.

15. Weinger S., and Akuri J., (2007), Cameroonian Women's Perceptions of Their Health Care Needs. Nordic Journal of African Studies, 16(1): 47-63.

16. Azuh D., Fayomi O., and Ajayi L., (2015), SocioCultural Factors of Gender Roles in Women's Healthcare Utilization in Southwest Nigeria. Open Journal of Social Sciences, 3(04): 105.

17. Aluko-Arowolo S.O., Ademiluyi I.A., (2015), Understanding Maternal Health in the Context of culture, Infrastructure and Development in Pluralististic Nigerian Society. International Journal of Humanities Social Science, 5(4) 